\title{
Epoxidation of Podocarpus Falcatus Oil by Sulphuric Acid Catalyst: Process Optimization and Physio-chemical Characterization
}

\author{
Yigezu Mekonnen \\ School of Chemical Engineering, Jimma Institute of Technology, Jimma University, Jimma, Ethiopia
}

\section{Email address:}

Yigezu338@gmail.com

\section{To cite this article:}

Yigezu Mekonnen. Epoxidation of Podocarpus Falcatus Oil by Sulphuric Acid Catalyst: Process Optimization and Physio-chemical Characterization. American Journal of Chemical Engineering. Vol. 9, No. 4, 2021, pp. 84-90. doi: 10.11648/j.ajche.20210904.12

Received: June 17, 2021; Accepted: July 13, 2021; Published: July 21, 2021

\begin{abstract}
Recently environmental awareness and reduction of world fossil fuel reserves have enforced the need to look for a replacement of mineral oils with environmentally friendly and nontoxic epoxy oil vegetable-based. The current study implies that Epoxidized podocarpus falcatus oil can be a substitute as a raw material for the production of a variety of chemicals and the replacement of petroleum products in composite matrices because of having high reactivity of oxirane ring. The podocarpus falcatus oil was obtained by using the solvent extraction method. In this present investigation, the extracted podocarpus falcatus oil was epoxidized using a performic acid generated in situ by the reaction of aqueous hydrogen peroxide and carboxylic acid in presence of strong Sulphuric acid. A maximum percentage of conversion of oil and selectivity of epoxidized oil were found to be at $63^{\circ} \mathrm{C}$ temperature, 1.4:1 molar ratio of hydrogen peroxide to ethylene unsaturation double bond of podocarpus falcatus oil, and 4 hours of time reaction. The effective synthesis of epoxidation reaction for confirmation on the investigation of epoxidized podocarpus falcatus oil was characterized by identifying the structure, functional group, and composition of podocarpus falcatus seed oil, in comparison to epoxidized podocarpus falcatus oil, using Fourier Transform Infrared Spectroscopy.
\end{abstract}

Keywords: Podocarpus Falcatus, Epoxidation, Epoxidized Podocarpus Falcatus Oil, Per Formic Acid

\section{Introduction}

Developing alternatives production of Epoxides from the petrochemical have different limitation related with environmental pollution, health hazards and economic problem because of its non-degradability and production cost. Supplementary, it is advantageous to produce and develop bio-based material from cheaper, available resources and renewable feedstock [1], This achieved via vegetable oils, for development and production of epoxy oil, to inhibit the problem emerged from unsustainable and nonrenewable resource, and also from polluted nature of environment [2]. The unique characteristics of natural renewable polyunsaturated triglyceride are having high viscosity, lubrication index [5]; flashy and smoke point, biodegradability and low evaporative loss and harmfulness, and an attractive natural resource for the synthesis and production of Epoxidized vegetable oil since they have low solidity cost, ready availability in nature in large quantity [4]; and have the capability of potential renewability and decomposition [3].

In general, most of the Epoxidized vegetable oil is produced from an edible vegetable oil because of its availability throughout the country [6]; and the properties of epoxidized vegetable oils obtained from these sources are related to the one which used as the epoxidized petroleum product substitute [7]. One important plant oil that can be used for raw material of this epoxide vegetable oil which contains an oil yield of more than 63\% is Podocarpus falcatus oil [8].

Podocarpus falcatus is the family of Podocarpaceae and belongs to the gymnosperms which means that no fruit layer is produced, the seeds are borne "naked" inside the cone $[8$, 9]. The oil from its seed can be extracted by using different extraction methods to optimize its yield for different 
applications such as for medicine as a treatment for gonorrhea and epoxy oil for different uses. Hence, due to a fewer group of epoxy number and poor cross-linking density of resultant of epoxidized vegetable of oil many vegetable oils cannot be used as renewable resources for different applications [10]. This problem leads to delays to custom epoxidized vegetable oils as suitable alternatives to conventional petroleum-based epoxy. [11, 12]. Therefore, the formation of cyclic ether at sites of a double bond of unsaturation of fatty acid or oil $(\mathrm{C}=\mathrm{C})$ and the addition of a peracids compound to get a three-member cyclic ring indicates the epoxidation reaction of vegetable oil in the formation of either oxirane ring [13] or oxirane cleavage [14]. Therefore, the present study is primarily the analysis of the conversion of double bonds to an epoxy group and selectivity of oxirane oxygen content through the rate formation of epoxy and ring cleavage.

\section{Material and Methods}

\subsection{Materials}

Podocarpus falcatus oil was extracted from podocarpus falcatus seed acquired from Adet Agricultural Research Centre, Bahr Dar area. Once the oil is extracted using organic solvents such as n-hexane, purification to remove free fatty acids was carried out using standard procedures [19] and characterized with different techniques. Analytical grade hydrogen peroxide, formic acid, and Sulphuric acid were purchased from Addis Ababa Kirkos Chemical Company.

\subsection{Equipment}

Fourier Transform Infrared Spectroscopy analysis was performed on a Nicolet model Protégé 460 Magna IR spectrometer. The analysis of the Podocarpus falcatus oil and epoxidized podocarpus falcatus oil was carried out with analytical grade $\mathrm{KBr}$ pellets using the transmission mode. All the spectra were recorded with $4 \mathrm{~cm}-1$ resolutions over 100 scans.

\subsection{Epoxidation Experiments}

Epoxidation of $p$. falcatus seed oil was carried out in a 500 $\mathrm{ml}$ three-neck glass reactor equipped with MSH-D hotplate magnetic stirrer, and thermometer. $P$. falcatus seed oil was charged with formic acid and concentrated Sulphuric acid in the glass. The epoxidation reaction was carried out by two steps consequently. Firstly, thirty percent of hydrogen peroxide solution (1.1:1 to $1.7: 1$ hydrogen peroxide to oil ratio) was dropped into mixtures slowly through a funnel over 30 minutes at a stirring speed of $850 \mathrm{rpm}$ and the oil was dissolved with the mixtures. Then, controlling the parameter like the temperature at 50 to $70^{\circ} \mathrm{C}$, reaction time 3 to $6 \mathrm{hr}$. and $1.1: 1$ to $1.7: 1$ hydrogen peroxide to oil ratio the epoxidation reaction was carried out. Then, analysis of physicochemical properties of epoxidized $p$. falcatus oil (formed product) such as functional group by FT-IR test, oxirane oxygen content, epoxide content, and iodine value were determined.

\subsection{Experimental Design for Epoxidized p. Falcatus Oil Production}

Experimental Data analysis has performed by design expert 6.8.0 software. The type of design expert-selected used to analyze the parameter variable such as reaction temperature, amount of hydrogen peroxide to oil ratio and reaction time of epoxidation reaction of podocarpus falcatus oil was 3-level-3-factor Box Behnken Design (BHD).

\subsection{Analytical Methods}

The titration method was done by direct titration of oxygen with hydrobromic acid in glacial acetic solution in order to know how much percentage of the oxirane oxygen content of epoxidized oil was formed from podocarpus falcatus oil by epoxidation reaction using AOCS Official Method Cd 9-57 (1997) [15].

$$
\text { OOC }=\frac{\mathrm{b} \times \mathrm{c}}{\mathrm{m}}
$$

Where, $b$ is the volume titrant of $(\mathrm{mL})$ of $\mathrm{HBr}$ glacial acetic acid solution, $\mathrm{c}(\mathrm{mol} / \mathrm{L})$ is the concentration of $\mathrm{HBr}$ glacial acetic acid solution, $\mathrm{m}$ is the mass $(\mathrm{g})$ of the sample.

$$
\begin{gathered}
\text { conversion } \%=\frac{\mathrm{Iv}_{\mathrm{o}}-\mathrm{IV}}{\mathrm{Iv}_{\mathrm{O}}} \times 100 \\
\mathrm{~S}_{\mathrm{p}}=\frac{\mathrm{OOC}}{\mathrm{OOC}_{\text {theo }}} \times \frac{\mathrm{IDo}}{\mathrm{IDo}-\mathrm{ID}} \times 100 \\
\text { OOCtheo }=\frac{\mathrm{ID}_{\mathrm{O}} / 2 \mathrm{AW}_{\mathrm{I}}}{100+\left(\frac{\mathrm{ID} O}{2 \mathrm{AW}}\right) \times \mathrm{AW}_{\mathrm{O}}} \times \mathrm{AW}_{\mathrm{O}} \times 100
\end{gathered}
$$

Where, $\mathrm{Sp}$ is the selectivity of the epoxidized oil, OOC is oxirane oxygen content of the epoxidized oil determined by experiment, OOCtheo is the theoretical value of oxirane oxygen content of the oil, AWi $=126.9$ is the molecular weights of iodine

$\mathrm{AWo}=16.0$ is the molecular weight of oxygen and

ID0 is the initial iodine value of the oil sample

\section{Result and Discussion}

\subsection{Effects of Temperature on Conversion of Double Bound and Selectivity of Epoxidized Oil}

As shown in figure 1(a) analysis influence of temperature on the conversion change of epoxy percentage that demonstrated the temperature of epoxidation reaction was the most important. From this figure, as temperature increase to some designed or limits point the reaction undergoes epoxidation was more favored and a maximum of $70.9 \%$ conversion of double bonds of unsaturated $p$. falcatus acid to epoxies oil-based iodine value was obtained at $60^{\circ} \mathrm{C}$ and at a reaction time of 4.5 hours. Nevertheless, as the temperature increase from 50 to $60^{\circ} \mathrm{C}$ the conversion was highly increased while it was reached the design space at $60^{\circ} \mathrm{C}$ the percentage of conversion then starts to drop as the 
temperature tend to increase above the center limit. This indicated that as temperature increase from 50 to $60^{\circ} \mathrm{C}$ iodine degradation rate was increased [14], These results related to, higher rate of depletion or disappearance [16]; bond occurred due to more rapid epoxidation with the establishment and use of peroxyformic acid in the reaction [17]. From these, we conclude that the epoxidation of $p$. falcatus oil seemed that the free radical chain of polymerization because as soon as the reaction begins while the formation of the polymerized or epoxidized of $p$. falcatus. In addition to the effects of temperature on conversion, the selectivity of epoxidized oil is significantly affected by increasing reaction temperature until it reaches its center value would result increasing in the percentage of selectivity, the percentage of selectivity then starts to drop as the temperature tend to increase above the center limit. Since selectivity has a direct relation with the oxirane value of an epoxy number that means at lower temperature its value was higher than at higher temperature. The result indicated that for epoxidation reaction an exothermic process is not recommended because using high Ratio of $\mathrm{H}_{2} \mathrm{O}_{2}$ to oil at higher temperatures lead to reaction would explosion. However, at low temperature $\left(50^{\circ} \mathrm{C}\right.$ and $\left.60^{\circ} \mathrm{C}\right)$, the selectivity (\%) getting up, but from the temperatures of $60^{\circ} \mathrm{C}$ the selectivity has decreased, it is because the temperature of the higher possible side reaction, so lowering the selectivity [18].

\subsection{Effect of Molar Ratio of Hydrogen Peroxide to Double Bond of P. Falcatus Oil}

From figure 1(b) and table 2 the molar ratio increases the selectivity percentage was increased. In another case, the concentration of hydrogen peroxide affects the stability of oxirane number or ring [19]. In addition to this, the degradation of epoxies group or oxirane ring cleavage was occurred due to the formation of water from the reaction between performic acid and hydrogen peroxide during epoxidation reaction was carried out as a result of the hydrolysis in acidic condition. According to the report [20]; using a high percentage and amount of $\mathrm{H}_{2} \mathrm{O}_{2}$ relative to the number of ethylene unsaturated fatty acid bonds is best to promote to get high selectivity and conversion of double bonds to epoxy ring or oxirane oxygen but beyond at temperatures of $60^{\circ} \mathrm{C}$ the degradation of hydrogen peroxide was occurred. As result shown in tables 1 and 2 based on changing the epoxy number and oxirane value, it is found that the molar ratio of $\mathrm{H}_{2} \mathrm{O}_{2}$ to oil equal to 1.7 was the most advantageous by using formic acid in order to forming the performic acid and in this case high epoxy number or oxirane value was achieved.

Table 1. Effects of Ratio of $\mathrm{H}_{2} \mathrm{O}_{2}$ to oil (1.1: to 1.7:1) at Constant Reaction Temperature and Time.

\begin{tabular}{|c|c|c|c|c|c|}
\hline Reaction Temperature & Ratio of $\mathrm{H}_{2} \mathrm{O}_{2}$ to Oil & Time $\mathbf{H r}$ & Iodine Value & Oxarine Number & Conversion \\
\hline 60.00 & $1.10: 1$ & 4.50 & 34.705 & 3.29 & 67.62 \\
\hline 60.00 & $1.4: 1$ & 4.50 & 31.1 & 4.05 & 70.89 \\
\hline 60.00 & $1.7: 1$ & 4.50 & 38.2 & 3.44 & 64.36 \\
\hline
\end{tabular}

Table 2. Effects of Time (3 to 6 hour) at Constant Reaction Temperature and Ratio of $\mathrm{H}_{2} \mathrm{O}_{2}$ to Oil.

\begin{tabular}{llllll}
\hline Reaction Temperature & Ratio of $\mathbf{H}_{2} \mathbf{O}_{2}$ to Oil & Time & Iodine Value & Oxarine Number & Conversion \\
\hline 60.00 & 1.40 & 3.00 & 41.33 & 2.92 & 61.4 \\
60.00 & 1.40 & 4.50 & 31.1 & 4.05 & 70.89 \\
60.00 & 1.40 & 6.00 & 33.8 & 3.8 & 68.46 \\
\hline
\end{tabular}

\subsection{Effects of Reaction Time on Epoxidation Reaction Process}

From figure 2 ( $a$ and $b$ ) as the reaction time increases the selectivity of oxirane value in fatty acid of podocarpus falcatus seed oil was increased until it reached its optimum value and starts to decrease when the reaction time increases above the limit center. From this result, we found that the selectivity of oxirane oxygen content or number of epoxies in oil high at the middle of reaction time and lower at higher reaction time and temperature. This is due to the formation of hydrolysis or oxirane degradation at a higher reaction time. With further increases in reaction time, the Oxirane Oxygen Content which has a direct relation with the selectivity of epoxidized podocarpus falcatus oil decreased which was attributed to more unwanted products or water being formed was taken to the undesirable oxirane ring cleavage or less in epoxy number in oil. According to [18]; At temperatures higher than the required reaction time is shorter, the number of epoxy content obtained was high at reaction time 4 hours, while the temperature reaction of $85^{\circ} \mathrm{C}$ and shorter time, Oxirane Oxygen content oil amount obtained was low during the epoxidation of soya bean.

\subsection{FTIR Spectrum Analysis of Epoxidized p. Falcatus Oil}

From figure 3 the presence or formation of peaks of vibration of the doubles bond for $p$. falcatus oil is generally formed at 3009,1653 , and $721-726 \mathrm{~cm}^{-1}$ for the indication of chemical bonding of $\mathrm{C}=\mathrm{C}-\mathrm{H}, \mathrm{C}=\mathrm{C}$, cis- $\mathrm{CH}=\mathrm{CH}$, respectively. After the epoxidation reaction was carried out the occurrence of the total diminishing of $\mathrm{C}=\mathrm{C}-\mathrm{H}$ stretching peaks at $3009 \mathrm{~cm}^{-1}$ occurred which indicated that almost there is the consumption of carbon-carbon double bond peak at $3009 \mathrm{~cm}^{-1}$. This means that due to a high amount of iodine value present in $p$. falcatus oil the epoxidation reaction was carried out by diminishing the $\mathrm{C}=\mathrm{C}-\mathrm{H}$. In moreover, the intensity of other unsaturated oil bonds was decreased due to the unreacted oil presented in the component of $p$. falcatus 
oil of its transformation to an oxirane ring. After epoxidation reaction was carried out a new peak was emerged in the spectrum of Epoxidized podocarpus oil at 1237- $1251 \mathrm{~cm}^{-1}$ and $823.2 \mathrm{~cm}^{-1}$, which indicated that the formation of the epoxy group (-C-O-C- epoxy functional group absorption band) since it is found between $1210-1320 \mathrm{~cm}^{-1}$ and the podocarpus oil was successfully undergone epoxidation reaction for the production of epoxy. From other views, there was another peak that determines about hydroxyl functional group at $3388 \mathrm{~cm}^{-1}[21]$.

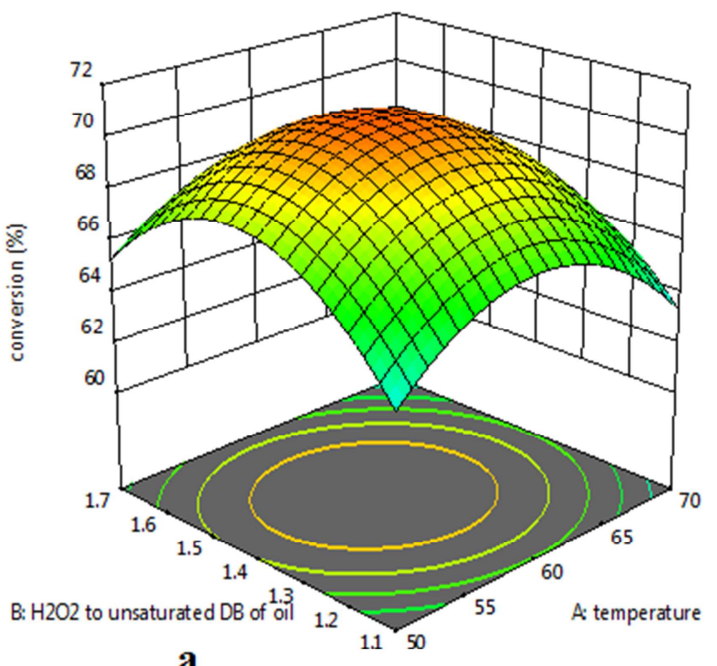

a

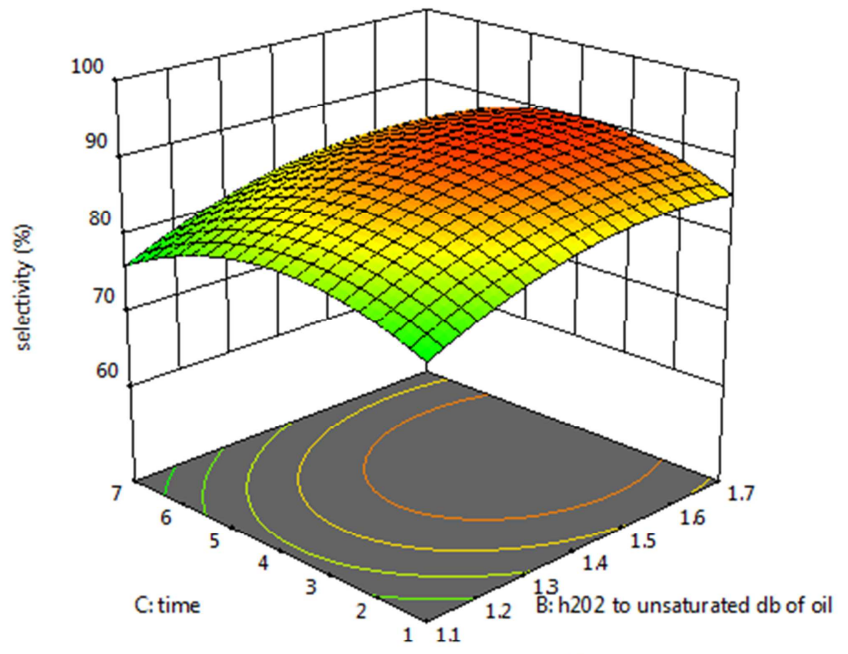

b

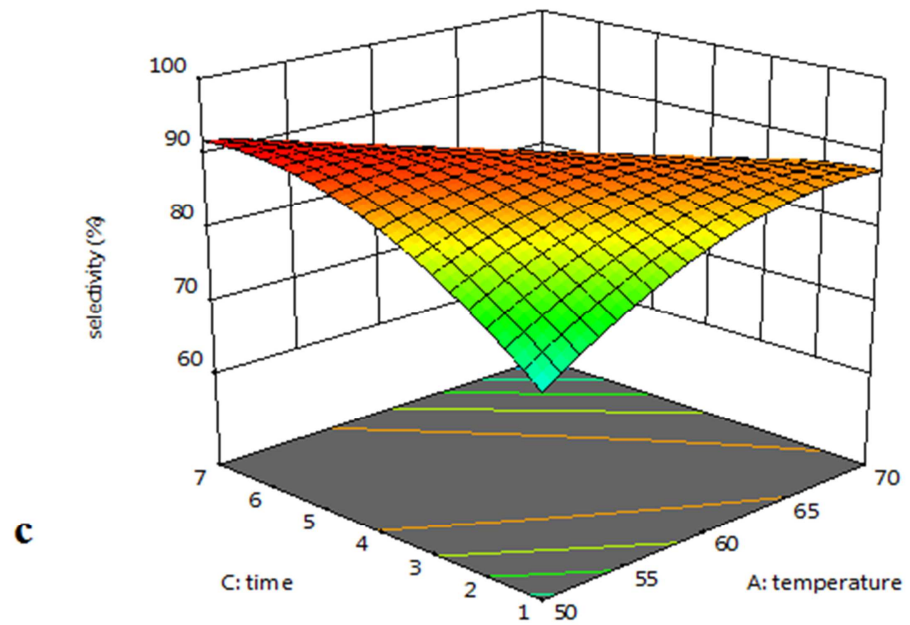

Figure 1. (a) - Percentage of conversion molar ratio of hydrogen peroxide to oil versus temperature (b) - Percentage of selectivity time versus the molar ratio of hydrogen per oxide to oil and. (c) -Percentage of selectivity time versus temperature.
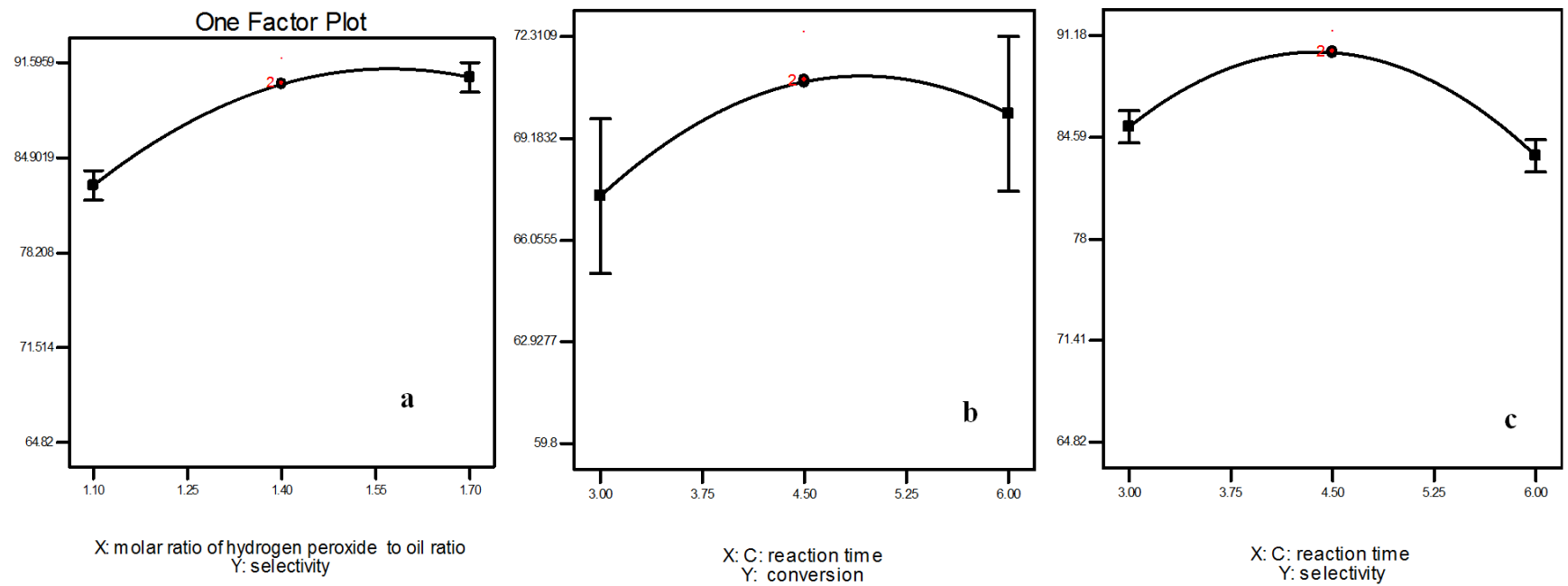

Figure 2. (a) Effects of reaction Molar ratios of $\mathrm{H}_{2} \mathrm{O}_{2}$ to oil on the selectivity of epoxidized oil on epoxidation reaction and Effects of reaction time on epoxidation reaction (b) conversion of double bond (c) selectivity of the epoxidized p. falcatus oil. 


\subsection{Kinetics and Thermodynamic Properties of Epoxidized of Podocarpus Falcatus Oil}

\subsubsection{Kinetic Parameter Calculation}

In this study of epoxidation reaction, there were only two steps involved: the first one is the formation of peroxyformic acid, and the other is the reaction of peroxyformic acid with the unsaturated double bond of the p. falcatus oil since the reaction involved was a homogeneous catalytic reaction.
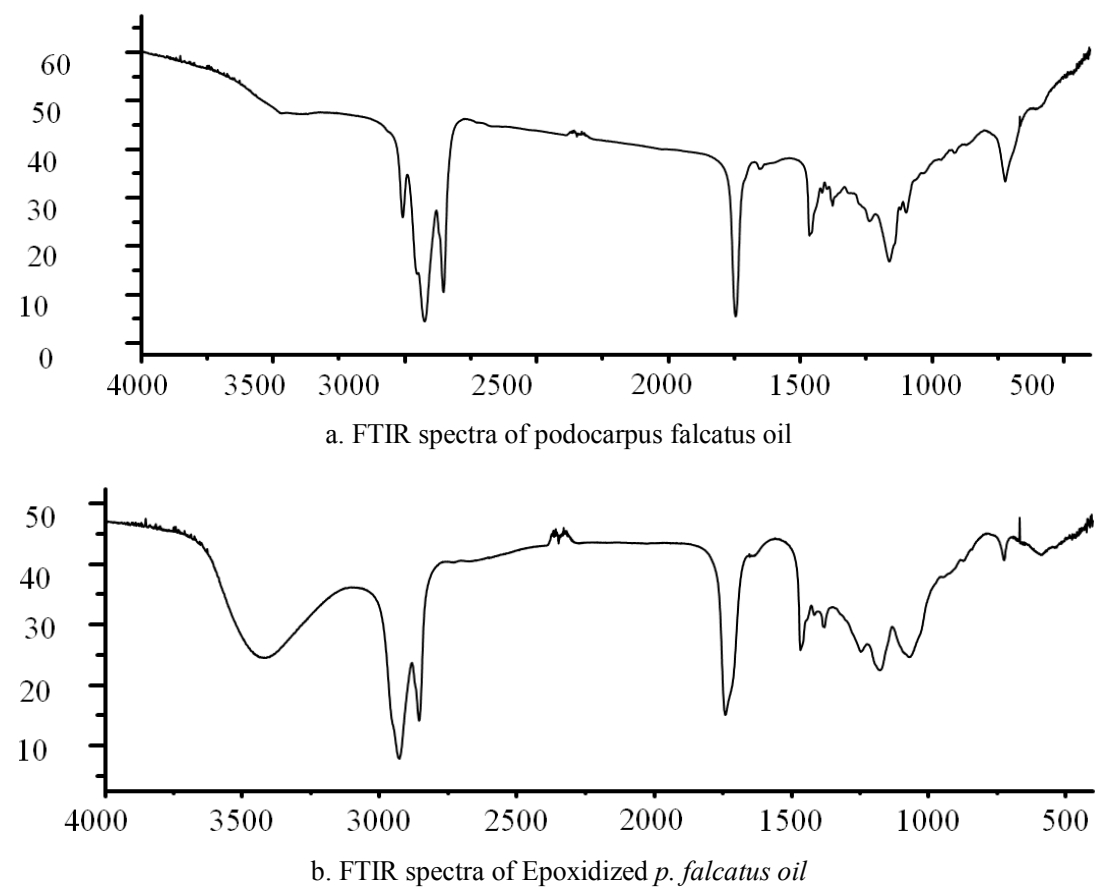

Figure 3. FTIR spectroscopy of p. falcatus (a) oil (b) epoxidized oil.

From these two steps reactions, the following assumptions were taken. The first step was considered rate-determining since the concentration of performic acid and $\mathrm{H}_{2} \mathrm{O}_{2}$ were assumed constant throughout the reaction. The kinetics model study was based on conversational of double bond from iodine value. (i) Formation of a peroxy acid.

$$
\mathrm{HCOOH}+\mathrm{H}_{2} \mathrm{O}_{2} \stackrel{K_{1} K_{2}}{\rightleftarrows} \mathrm{HCOOOH}+\mathrm{H}_{2} \mathrm{O}
$$

(ii) formation of Epoxidized oil

$$
\mathrm{HCOOH}+\mathrm{R}_{1}-\mathrm{C}=\mathrm{C}-\mathrm{R}_{2} \Leftrightarrow \mathrm{R}_{1}-\mathrm{CH}(\mathrm{OH}) \mathrm{CH}\left(\mathrm{OCOCH}_{3}\right)-\mathrm{R}_{2}+\mathrm{HCOOH}
$$

To determine the order of the reaction let us drive the general equation for epoxidation reaction for the two steps.

$$
\begin{gathered}
\frac{d}{\mathrm{dt}}[\mathrm{OO}]=\mathrm{k}\left\{\left\{\left[\mathrm{H}_{2} \mathrm{O}_{2}\right]_{0}-[\mathrm{OO}]\right\} \cdot[\mathrm{HCOOH}]\right. \\
\ln \left\{\left[\mathrm{H}_{2} \mathrm{O}_{2}\right]_{0}-[\mathrm{OO}]\right\}=-\mathrm{K}[\mathrm{CHOOH}] \mathrm{t}+\ln \left[\mathrm{H}_{2} \mathrm{O}_{2}\right]_{0}
\end{gathered}
$$

where $[\mathrm{OO}]$ is the concentration of oxirane oxygen, $\left[\mathrm{H}_{2} \mathrm{O}_{2}\right]_{0}$ initial concentration of hydrogen peroxide, and $[\mathrm{HCOOH}]$ is the concentration of formic acids.

The concentration of formic acid is assumed to remain constant due to the dissociation constant of formic acid and the equilibrium constant is small which leads to a reaction with negligible degradation of oxirane. But reaction between hydrogen peroxide and formic acid was leading cause the formation of per hydrolysis. So, the rate constant of the ring- opening reaction was determined at different temperatures. From the rate law,

$$
\ln \left\{\left[\mathrm{H}_{2} \mathrm{O}_{2}\right]_{0}-[\mathrm{OO}]\right\}=-\mathrm{K}[\mathrm{HCOOH}] t,
$$

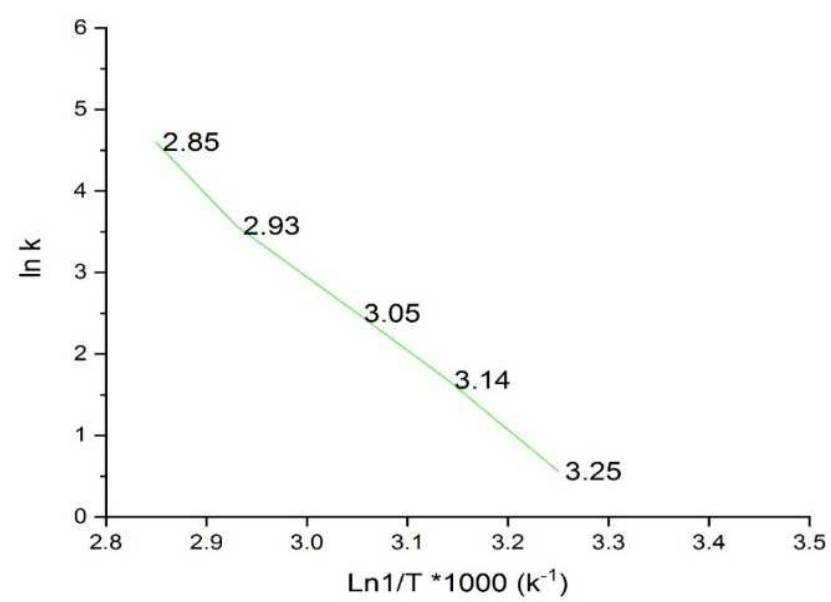

Figure 4. Activation Energy, Ea for the Epoxidation of Podocarpus Falcatus Oil.

At different temperature rates constant was calculated. Therefore, by applying the Arrhenius equation the activation energy was calculated from the slope of the graph of lnk vs $\ln 1 / T$. During the epoxidation of podocarpus falcatus oil, the required input of energy was lower because of using Sulphuric acid catalysis. 


\subsubsection{Thermodynamic Calculation}

The enthalpy of activation and entropy were calculated using the equation

$$
\begin{gathered}
\Delta H=E a-R T \\
\Delta G=\Delta H-T \Delta S
\end{gathered}
$$

So, $\Delta H=$ to be $15.12 \mathrm{kcal} \mathrm{mol}^{-1}$, the average entropy and activation energy were calculated by using the equation frost and Pearson

$$
K=\frac{R T}{N h} e^{\Delta s / R} e^{-E / R T}
$$

where $k$, rate constant; $R$, gas constant; $T$, absolute temperature; $N$, Avogadro constant; and $h$, Planck constant. The activation energy was obtained from figure 4 . So, $\Delta S=-$ $31.94 \mathrm{Cal} \mathrm{mol}^{-1} \mathrm{~K}^{-1}=$ and $\Delta G=23.22 \mathrm{kcal} / \mathrm{mol}$. Therefore, depending on the result of Gibbs free energy the reaction was endergonic or not spontaneous which indicated that the positive effects of temperature on the conversion to oxirane oxygen. However, the net conversion to oxirane will maximize if the in-situ epoxidation occurs at optimum temperature, which depends on the type of catalyst used.

\section{Conclusion}

The FTIR analysis is an influential tool and supports the effective synthesis of epoxidation reaction for confirmation on the investigation of the number of double bonds (unsaturation) which was used to correlate it with the epoxy number and epoxidation percentage of the oils. The outcomes of the epoxidation of podocarpus falcatus oil are imperative for the chemical industry and the effect of process variables such reaction temperature, the molar ratio of hydrogen peroxide to double bond of oil, and reaction time on conversion of the carbon double bond of oil to epoxidized $\mathrm{p}$. falcatus oil based on iodine value and its selectivity was investigated. At a reaction temperature of $63^{\circ} \mathrm{C}$, the molar ratio of hydrogen peroxide to oil 1.4:1 and reaction time of 4 hours an optimal value of $71.9 \%$ percentage of conversion and $90.98 \%$ of selectivity were obtained. The FTIR analysis was found to be useful in confirming the disappearance of $\mathrm{C}=\mathrm{C}$ - and formation of C-O-C epoxy functional groups at $1237-1251 \mathrm{~cm}^{-1}$ and $823.2 \mathrm{~cm}^{-1}$ absorption band region.

\section{Recommendation}

1) Epoxidation by enzymatic epoxidation reaction can increase the conversion and selectivity of epoxidized $p$. falcatus oil from $p$. falcatus seed oil. For capable of converting vegetable oil into epoxy oil by using enzymatic epoxidation method is recommended.

2) Homogeneous epoxidation reaction is related to environmental issues. Therefore, investigations on heterogeneous catalysts should be applied to avoid environmental pollution during epoxidation reactions.

3) Further study on improvement of the epoxidation process parameters catalyst loading, molar ratio of formic acid to oil, and speed of agitator on the percentage of conversion and selectivity is also suggested

\section{References}

[1] Bakthavachalam, A., Beyene, S. D. \& Gopal, V. Industrial Crops \& Products Green epoxy synthesized from Perilla frutescens: A study on epoxidation and oxirane cleavage kinetics of high-linolenic oil. Ind. Crop. Prod. 123, 25-34 (2018).

[2] Chang, C., Qin, Y., Luo, X. \& Li, Y. Synthesis and process optimization of soybean oil-based terminal epoxides for the production of new biodegradable polycarbonates via the intergration of CO 2. Ind. Crop. Prod. 99, 34-40 (2017).

[3] Thompson, A. E., Dierig, D. A. \& Kleiman, R. Characterization of Vernonia galamensis germplasm for seed oil content, fatty acid composition, seed weight, and chromosome number. Ind. Crops Prod. 2, 299-305 (1994).

[4] Jankovi, M. R., Govedarica, O. M. \& Sinadinovi, V. The epoxidation of linseed oil with in situ formed peracetic acid: A model with included in $\mathrm{fl}$ uence of the oil fatty acid composition. Ind. Crops Prod. 143, (2020).

[5] Dinda, S., Patwardhan, A. V, Goud, V. V \& Pradhan, N. C. Epoxidation of cottonseed oil by aqueous hydrogen peroxide catalyzed by liquid inorganic acids. Bioresource. Technol. 99, 3737-3744 (2008).

[6] Cousin, T., Chatel, G., Kardos, N., Andrioletti, B. \& Draye, M. Ultrasonics - Sonochemistry High frequency ultrasound as a tool for elucidating mechanistic elements of cis -cyclooctene epoxidation with aqueous hydrogen peroxide. Ultrason. Sonochemistry 53, 120-125 (2019).

[7] Wang, R. Scholars ' Mine Manufacturing of vegetable oilsbased epoxy and composites for structural applications. (2014).

[8] Feleke, S., Haile, F., Alemu, A. \& Abebe, S. Characteristics of seed kernel oil from podocarpus. 24, 512-516 (2012).

[9] Tadele, D. \& Fetene, M. Growth and ecophysiology of seedlings of Podocarpus falcatus in planta- tions of exotic species and in a natural montane forest in Ethiopia. 24, (2013).

[10] Kazemnejadi, M. Synthesis and characterization of a new poly a -amino acid Co (II) -complex supported on magnetite graphene oxide as an ef fi cient heterogeneous magnetically recyclable catalyst for ef fi cient free-coreductant gram-scale epoxidation of ole fi ns with. Organomet. Chem. 896, 59-69 (2019).

[11] Cavoué, T. Electrochemistry Communications Ethylene epoxidation on $\mathrm{Ag} \mathrm{/} \mathrm{YSZ} \mathrm{electrochemical} \mathrm{catalysts:}$ Understanding of oxygen electrode reactions. Electrochem. commun. 105, 106495 (2019).

[12] Mohammadikish, M., Yarahmadi, S. \& Molla, F. A new waterinsoluble coordination polymer as efficient dye adsorbent and olefin epoxidation catalyst. J. Environ. Manage. 254, 109784 (2020).

[13] Gamage, P. K., Brien, M. O. \& Karunanayake, L. Epoxidation of some vegetable oils and their hydrolysed products with peroxyformic acid - optimised to industrial scale. 37, 229-240 (2009). 
[14] Liu, Z., Erhan, S. Z. \& Xu, J. Preparation, characterization and mechanical properties of epoxidized soybean oil / clay nanocomposites *. Polymer (Guildf). 46, 10119-10127 (2005).

[15] Meshram, P. D., Puri, R. G. \& Patil, H. V. Epoxidation of Wild Safflower (Carthamus oxyacantha) Oil with Peroxy acid in presence of strongly Acidic Cation Exchange Resin IR- 122 as Catalyst. 3, 1152-1163 (2011).

[16] Guo, Y. Binuclear molybdenum Schi ff -base complex: An efficient catalyst for the epoxidation of alkenes. Mol. Catal. 475, 1-7 (2019).

[17] Xie, W. \& Chai, X. Determination of epoxy groups in epoxy resins by reaction-based headspace gas chromatography. Polymer Test. 59, 113-117 (2017).
[18] Nugrahani, R. A., Redjeki, A. S., Mentari, Y., Jannah, M. \& Wibowo, T. Y. Study effect of temperature and reaction kinetics model selection epoxidation against rice bran oil methyl ester with catalyst amberlite iR-120. 12, 3947-3952 (2017).

[19] Engel, R. V Solvent-free aerobic epoxidation of 1-decene using supported cobalt catalysts. Catal. Today 1-7 (2018) doi: 10.1016/j.cattod.2018.09.005.

[20] Milchert, E., Malarczyk, K. \& Kłos, M. Technological Aspects of Chemoenzymatic Epoxidation of Fatty Acids, Fatty Acid Esters and Vegetable Oils: A Review. 21481-21493 (2015) doi: 10.3390/molecules201219778.

[21] Samarth, N. B. Available online a t www.scholarsresearchlibrary.com Scholars Research Library Scholars Research Library. 8, 1-7 (2016). 